\title{
Nephrology
}

\section{Erythropoietin Hyporesponsiveness in Dialysis Patients: Possible Role of Statins}

\author{
Takeshi Hasegawa $^{\text {a, c-f }}$ Junhui Zhao ${ }^{g}$ Douglas S. Fullerg Brian Bieber $^{g}$ \\ Jarcy Zee ${ }^{g}$ Hal Morgenstern ${ }^{\text {h }}$ Norio Hanafusa ${ }^{c, i}$ Masaomi Nangaku ${ }^{\text {b, } c}$

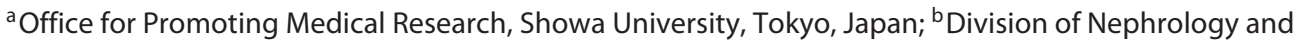 \\ Endocrinology, The University of Tokyo Graduate School of Medicine, Tokyo, Japan; ' Anemia Working Group of the \\ Japan Dialysis Outcomes and Practice Patterns Study (JDOPPS), Tokyo, Japan; ${ }^{d}$ Division of Nephrology, Department \\ of Medicine, Showa University Fujigaoka Hospital, Yokohama, Japan; ${ }^{\mathrm{e} C e n t e r ~ f o r ~ I n n o v a t i v e ~ R e s e a r c h ~ f o r ~}$ \\ Communities and Clinical Excellence, Fukushima Medical University, Fukushima, Japan; ${ }^{\mathrm{f} D e p a r t m e n t}$ of Healthcare \\ Epidemiology, School of Public Health in the Graduate School of Medicine, Kyoto University, Kyoto, Japan; \\ ${ }^{g}$ Arbor Research Collaborative for Health, Ann Arbor, MI, USA; h Departments of Epidemiology and Environmental \\ Health Sciences, School of Public Health, and Department of Urology, Medical School, University of Michigan, \\ Ann Arbor, MI, USA; 'Department of Blood Purification, Tokyo Women's Medical University, Tokyo, Japan
}

\section{Keywords}

Statins · Erythropoietin $\cdot$ Anemia $\cdot$ Hemodialysis

\begin{abstract}
Background: Hypothesizing that statins may be useful as adjuvant treatment for renal anemia, we examined the association between statin prescription (Rx) and erythropoiesis-stimulating agent (ESA) hyporesponsiveness in Japanese hemodialysis (HD) patients prescribed ESAs. Methods: We examined 3,602 patients in $60 \mathrm{HD}$ facilities dialyzed 3 times/ week for $\geq 4$ months from the Japan Dialysis Outcomes and Practice Patterns Study phases 3-5 (2005-2015). Statin Rx was reported at the end of a 4-month interval (baseline) for each patient. ESA hyporesponsiveness in the subsequent 4 months was then defined as a binary indicator (mean hemoglobin [Hgb] level $<10 \mathrm{~g} / \mathrm{dL}$ and mean ESA dose $>6,000$ units/week) and separately as the ESA resistance index (ERI; mean ESA dose/[dry weight $\times$ mean $\mathrm{Hgb}]$ ]). We used adjusted logistic and linear regressions to evaluate the associations between statin Rx and ESA hyporesponsiveness. Results: At baseline, $16.2 \%$ of patients reported statin Rx; $12.8 \%$ were classified as having ESA hyporesponsiveness during
\end{abstract}

\section{KARGER}

E-Mail karger@karger.com www.karger.com/ajn
(C) 2017 The Author(s)

Published by S. Karger AG, Basel

This article is licensed under the Creative Commons AttributionNonCommercial-NoDerivatives 4.0 International License (CC BYNC-ND) (http://www.karger.com/Services/OpenAccessLicense) tribution of modified material requires written permission.
4 months of follow-up. Compared to patients without statin $\mathrm{Rx}$, patients with statin Rx had lower odds of ESA hyporesponsiveness (OR 0.87; 95\% Cl 0.66-1.15). Similarly, the ERI was lower for those with statin Rx than without (ratio of means, $0.94 ; 95 \% \mathrm{Cl} 0.89-0.99$ ) after adjustment for possible confounders. Conclusions: Our results suggest that statins may slightly reduce ESA hyporesponsiveness in HD patients. However, any causal inference is limited by the observational study design and unmeasured compliance with statin Rx.

(C) 2017 The Author(s)

Published by S. Karger AG, Basel

\section{Introduction}

Cumulative evidence supports the efficacy and safety of lipid-lowering therapy with statins in patients with normal or modestly reduced renal function $[1,2]$. A meta-analysis showed that statins decreased the risk of mortality in early-stage chronic kidney disease (CKD) patients [2]. However, several randomized controlled trials in hemodialysis (HD) patients have shown no clinical benefit of lipid-lowering therapy with statins $[3,4]$. Further, a recent meta-analysis found that statins had little or

Takeshi Hasegawa, MD, MPH, PhD

Associate Professor, Office for Promoting Medical Research, Showa University 1-5-8 Hatanodai, Shinagawa-ku, Tokyo 142-8555 (Japan)

E-Mail tahasegawa-npr@umin.net 
no effect on reducing the mortality rate or risk of cardiovascular events in patients on dialysis [5]. Accordingly, the latest Kidney Disease: Improving Global Outcomes (KDIGO) guidelines now advise against starting statin use in dialysis patients [6]. However, the findings of an observational study have indicated that statin prescription was associated with reduced mortality in HD patients [7]. The current clinical guidelines $[6,8]$ do not recommend initiating statin use in dialysis patients but also do not require that patients cease taking statins upon initiating dialysis. Therefore, it seems reasonable to expect a certain proportion of dialysis patients to have a valid statin prescription for mortality and cardiovascular disease (CVD) risk reduction. Indeed, the United States (US) Dialysis Outcomes and Practice Patterns Study (DOPPS) Practice Monitor indicates that $45-50 \%$ of US HD patients were prescribed statins as of 2016 [9].

Statins have pleiotropic effects, including anti-inflammatory and anti-oxidative actions [10-12]. Statins may, therefore, be effective as an adjuvant treatment for renal anemia in HD patients. However, only a few small-scale, short-term, before-after studies have published findings suggesting that statins lead to the improvement in erythropoiesis-stimulating agent (ESA) responsiveness in HD patients [13-15]. Therefore, its clinical effectiveness for ESA resistance remains controversial in this population.

Hypothesizing that statins may indeed improve ESA efficacy in hyporesponsive patients, in this study, we examined the association between statin prescription $(\mathrm{Rx})$ and ESA hyporesponsiveness in Japanese HD patients prescribed ESAs in the Japan DOPPS (JDOPPS) cohort.

\section{Materials and Methods}

Study Design, Population, and Data Source

JDOPPS is a nationally representative prospective cohort study of randomly selected, prevalent HD patients aged 18 years or older from facilities across Japan. JDOPPS applies a common protocol with standardized questionnaires to capture detailed longitudinal patient-level information, as well as dialysis-facility practices and processes of care. We obtained demographic, clinical, and medication data from JDOPPS phases 3 (2005-2008), 4 (2009-2011), and 5 (2012-2015). This data source includes clinical data collection for approximately 7,000 Japanese HD patients from 58 to 62 dialysis facilities per phase of data collection.

Prevalent JDOPPS patients who were prescribed HD at a frequency of 3 times per week and had been on HD for at least 4 months were eligible for analysis $(n=6,625)$. Patients who died within 4 months of follow-up, who had polycystic kidney disease as a primary cause of ESRD, or who had a history of malignancy, gastrointestinal bleeding, liver disease, HIV, or prior transplant were excluded $(n=1,906)$. Baseline for each patient was defined as the time of JDOPPS study entry or the first time after JDOPPS study entry at which the patient was on HD for at least 4 months. Patients were required to have ESA administered at baseline as well as at each month during the subsequent 4-month period, referred to as the "outcome period" $(n=3,803)$. Patients with missing statin data at baseline or any missing data on hemoglobin ( $\mathrm{Hgb})$, postdialysis weight, or ESA dose in the outcome period were excluded $(n=3,602)$.

\section{Primary Exposure}

The primary exposure of interest was having a statin prescription at baseline. The JDOPPS medications database was searched for the following terms to identify statins (including commercial names and drug combinations [e.g., Vytorin] as necessary): atorvastatin, fluvastatin, HMG-CoA reductase inhibitors, lovastatin, pravastatin, rosuvastatin, and simvastatin.

\section{Primary Outcome}

The primary outcome of interest was ESA hyporesponsiveness in the outcome period. ESA hyporesponsiveness was defined dichotomously as mean $\mathrm{Hgb}<10 \mathrm{~g} / \mathrm{dL}$ and a standardized mean ESA dose $>6,000$ units/week during the outcome period [16]. We also measured the ESA resistance index (ERI) $[17,18]$ in the outcome period, calculated as ERI = mean ESA dose (units/week)/(dry weight $[\mathrm{kg}] \times$ mean $\mathrm{Hgb}[\mathrm{g} / \mathrm{dL}])$, where the dry weight was the postdialysis body weight averaged across 3 dialysis sessions at the end of the outcome period. For a given Hgb level and dry weight, higher ERI values indicate a greater ESA dose requirement. Because single-month ESA and Hgb values may not reflect the "usual" or targeted values, we used the average of monthly ESA doses and $\mathrm{Hgb}$ values during the outcome period to define these outcomes.

The ESA prescription was obtained monthly in the JDOPPS and standardized to a weekly dose. In Japan, ESAs used to treat anemia include "short-acting" epoetin alfa (and certain biosimilars), "long-acting" darbepoetin alfa, and Mircera (pegylated epoetin beta; Merck). To standardize the ESA dose between these different preparations, we converted Mircera doses to darbepoetin doses using a 1.2:1 ratio [19] and converted darbepoetin doses to epoetin doses using a 250:1 ratio [20].

\section{Covariates}

The following covariates were assessed during the baseline period: age, gender, years on dialysis (vintage), and 11 summary comorbidities (coronary artery disease, other CVD, cerebrovascular disease, congestive heart failure, diabetes, hypertension, lung disease, neurologic disease, psychiatric disorder, peripheral vascular disease, recurrent cellulitis/gangrene), albumin, transferrin saturation, ferritin, C-reactive protein (CRP), treatment time per session, single-pool Kt/V, hospitalization in the past 3 months, and postdialysis weight.

\section{Analysis Models}

The association between statin prescription in the baseline period and ESA hyporesponsiveness in the outcome period was estimated using logistic generalized estimating equations regression models, with an exchangeable working covariance matrix to account for within-facility patient clustering. The association between statin prescription in the baseline period and ERI was estimated using linear mixed regression models with a random inter- 
cept for each study facility. Because the ERI in the outcome period was not normally distributed, we used the log-transformed ERI in the regression models.

For each outcome, we estimated the effect of statin prescription with increasing levels of covariate adjustment in 4 models (see footnotes in Table 2 for adjustments). To compare patients prescribed a statin with those not prescribed a statin, we reported the adjusted odds ratios for ESA hyporesponsiveness and adjusted ratios of means for ERI.

Statins are thought to exhibit anti-inflammatory properties, which might indirectly influence ESA hyporesponsiveness. Therefore, we also examined whether CRP was a mediator of the effect of statin prescription on ESA hyporesponsiveness. The mediation analysis was conducted using the SAS mediation macro developed by Valeri and Vanderweele [21].

\section{Treatment of Missing Data}

We used the Sequential Regression Multiple Imputation Method implemented by IVEware to create an augmented dataset with 10 imputed values for each missing covariate value [22]. Analyses were conducted independently for each imputed dataset and combined using Rubin's rules [23] as implemented by the SAS MIAnalyze procedure in SAS/STAT 9.3 [24]. The statin prescription and outcome variables, including ESA dose and Hgb levels, were not imputed but were included in the imputation models.

\section{Ethical Considerations}

The Ethics Committee of Tokyo Women's Medical University approved the JDOPPS as a lead-managing institution (approval number: \#678), and the institutional review boards at each facility also approved the study, as required. Informed consent was obtained for each sampled patient in accordance with the requirements of the institutional review board and facility. Data collection was performed in a manner that maintained patient anonymity.

\section{Results}

\section{Statin Prescription and Patient Characteristics}

A total of 3,602 patients met the inclusion criteria. Baseline patient characteristics by statin prescription are listed in Table 1. During the baseline period, $16.2 \%$ $(585 / 3,602)$ of patients were prescribed a statin. Compared to those not prescribed a statin, patients who were prescribed a statin were more likely to be female, have larger body mass index, have shorter dialysis vintage, and have coronary artery disease, diabetes mellitus, or hospitalization in the 3 months prior to the baseline period. Patients prescribed a statin had lower levels of total cholesterol and low-density lipoprotein cholesterol and higher levels of high-density lipoprotein cholesterol and triglycerides than those not prescribed a statin. Serum albumin, CRP, treatment time per HD session, single pool $\mathrm{Kt} / \mathrm{V}$, and intravenous iron use and dose were similar between the 2 Rx groups.

Statins and ESA Hyporesponsiveness

\section{Association between Statin Prescription and}

ESA Hyporesponsiveness

ESA hyporesponsiveness, which was defined as $\mathrm{Hgb}$ $<10 \mathrm{~g} / \mathrm{dL}$ and standardized mean ESA dose $>6,000$ units/ week during the outcome period, was observed in $12.8 \%$ $(460 / 3,602)$ of patients. The proportion with ESA hyporesponsiveness was $11.3 \%$ in patients prescribed a statin and $13.1 \%$ in patients not prescribed a statin. Table 2 shows the estimated associations between statin prescription and subsequent ESA hyporesponsiveness with increasing levels of covariate adjustment. The odds of ESA hyporesponsiveness for patients prescribed a statin was $12-15 \%$ lower than for patients not prescribed a statin, depending on the covariate adjustment; for example, in model 4, the fully adjusted OR was 0.87 (95\% CI 0.66-1.15; Table 2a).

ESA resistance measured by ERI was $5-8 \%$ lower in patients with statin prescription compared with patients without statin prescription (models 3 and 4, adjusted ratio of means $=0.94 ; 95 \%$ CI 0.89-0.99; Table $2 b$ ).

Results of the CRP mediation analyses indicated that there was no CRP-mediated indirect effect of statin prescription on ESA hyporesponsiveness, as statins are not significant in predicting CRP.

\section{Discussion}

We investigated the association between statin prescription and ESA hyporesponsiveness using a representative cohort of Japanese maintenance HD patients enrolled in JDOPPS phases 3-5 (2005-2015). A total of $16.2 \%$ of patients reported statin prescription at baseline period, and $12.8 \%$ were classified as having ESA hyporesponsiveness during follow-up (outcome period). Our results showed that HD patients prescribed statins were slightly less likely than patients not prescribed statins to exhibit ESA hyporesponsiveness during the following 4 months (outcome period) than those not prescribed statins, even after adjusting for potential confounders, including indices of iron metabolism, inflammation, and nutrition status.

As expected, our findings are similar to those of previous small-scale investigations mentioned below. A retrospective cohort study at a single US center first described the possibility of a clinical effect of statin therapy on reducing ESA requirements in HD patients [13]. These authors compared the ESA dose pre- and post-statin therapy among 19 patients and showed that the ESA requirement had decreased by a mean of $25 \%$ after therapy. A beforeafter observational study at a single center in Greece re-

Am J Nephrol 2017;46:11-17 
Table 1. Baseline patient characteristics classified by statin prescription; JDOPPS phases 3-5 (2005-2015)

\begin{tabular}{|c|c|c|}
\hline Characteristic & Prescribed a statin & Not prescribed a statin \\
\hline Number of patients, $n(\%)$ & $585(16.2)$ & $3,017(83.8)$ \\
\hline \multicolumn{3}{|l|}{ Demographics } \\
\hline Age, years & $63.8(11.9)$ & $63.7(12.5)$ \\
\hline Male, $\%$ & 52 & 63 \\
\hline $\mathrm{BMI}, \mathrm{kg} / \mathrm{m}^{2}$ & $22.6(4.0)$ & $21.2(3.3)$ \\
\hline Time on dialysis, years & $4.63(5.55)$ & $7.08(6.73)$ \\
\hline \multicolumn{3}{|l|}{ Comorbidities, $\%$} \\
\hline Coronary artery disease & 39 & 29 \\
\hline Other cardiovascular disease & 21 & 25 \\
\hline Cerebrovascular disease & 15 & 13 \\
\hline Congestive heart failure & 22 & 19 \\
\hline Diabetes mellitus & 55 & 37 \\
\hline Hypertension & 83 & 80 \\
\hline Lung disease & 2 & 4 \\
\hline Neurological disease & 8 & 8 \\
\hline Psychiatric disorder & 3 & 4 \\
\hline Peripheral vascular disease & 15 & 14 \\
\hline Recurring cellulitis/gangrene & 3 & 3 \\
\hline Hospitalization in the past 3 months & 18 & 12 \\
\hline \multicolumn{3}{|l|}{ Lab measurements } \\
\hline Albumin, g/dL & $3.74(0.37)$ & $3.74(0.39)$ \\
\hline TSAT, $\%$ & $23.0(16.8-31.0)$ & $24.2(18.0-32.9)$ \\
\hline Ferritin, ng/mL & $87.0(37.0-185.0)$ & $99.5(41.9-213.0)$ \\
\hline $\mathrm{CRP}, \mathrm{mg} / \mathrm{L}$ & $1.00(0.50-3.00)$ & $1.00(0.50-3.00)$ \\
\hline Total cholesterol, mg/dL & $151(34)$ & $157(35)$ \\
\hline LDL cholesterol, mg/dL & $76.0(26.1)$ & $84.7(28.7)$ \\
\hline HDL cholesterol, mg/dL & $48.3(16.0)$ & $47.6(15.7)$ \\
\hline Triglycerides, mg/dL & $128(73)$ & $119(126)$ \\
\hline \multicolumn{3}{|l|}{ Treatment } \\
\hline Treatment time per session, $\min$ & $237(28)$ & $236(28)$ \\
\hline Single pool, Kt/V & $1.37(0.28)$ & $1.38(0.28)$ \\
\hline IV iron use, $\%$ & 27 & 27 \\
\hline IV iron dose, mg/month* & $204(129)$ & $201(146)$ \\
\hline
\end{tabular}

BMI, body mass index; JDOPPS, Japan Dialysis Outcomes and Practice Patterns Study; CRP, C-reactive protein; LDL, low-density lipoprotein; HDL, high-density lipoprotein; TSAT, transferrin saturation; IV, intravenous.

Continuous variables are expressed as mean (SD) or median (interquartile range). Categorical variables are expressed as percentages.

* Among patients prescribed IV iron.

ported that atorvastatin prescription for 9 months improved ESA hyporesponsiveness among 33 iron-repleted HD patients [15]. Another group of investigators found in their before-after study at a single Taiwanese HD unit that atorvastatin prescription for 4 months decreased the erythropoietin-to-hematocrit ratio among 30 patients with hyperlipidemia [14]. That study also found that statin prescription was associated with a decrease in the levels of proinflammatory cytokines, such as interleukin- 6 and tumor necrotic factor-alpha.

A recent JDOPPS study showed that low-grade inflammation status represented by mild CRP elevation was related to future incidence of ESA hyporesponsiveness
[25]. A retrospective cohort study of 1,754 patients receiving care at chain facilities in North America showed that elevated the CRP level was related to higher subsequent ESA dose requirements after adjusting for potential confounders [26]. However, another cohort study among HD patients found that statin prescription improved ESA hyporesponsiveness without a reduction in CRP levels [15]. We conducted a mediation analysis, but our results indicated that CRP did not mediate the effect of statin therapy on subsequent ESA hyporesponsiveness, as statins are not significant for predicting CRP.

A clear definition of ESA hyporesponsiveness has not yet been established, and guidelines have used different
14

Am J Nephrol 2017;46:11-17 DOI: $10.1159 / 000477217$
Hasegawa/Zhao/Fuller/Bieber/Zee/ Morgenstern/Hanafusa/Nangaku 
Table 2.

a Association between statin prescription and subsequent ESA hyporesponsiveness by increasing levels of adjustment

\begin{tabular}{|c|c|c|c|c|c|c|c|}
\hline \multirow[t]{2}{*}{ Outcome } & \multirow[t]{2}{*}{ Statin $\mathrm{Rx}$} & \multirow[t]{2}{*}{ Number of patients } & \multirow{2}{*}{$\begin{array}{l}\text { Number of events, } \\
n(\%)\end{array}$} & \multicolumn{4}{|l|}{ OR (95\% CI) } \\
\hline & & & & model $1^{b}$ & $\operatorname{model} 2^{c}$ & model $3^{\mathrm{d}}$ & $\operatorname{model} 4^{\mathrm{e}}$ \\
\hline $\begin{array}{l}\mathrm{Hgb}<10 \mathrm{~g} / \mathrm{dL} \\
\mathrm{ESA} \text { dose } \mathrm{a}^{\mathrm{a}}>6,000 \\
\text { units/week }\end{array}$ & + & 585 & $66(11.3)$ & $0.88(0.67-1.13)$ & $0.86(0.65-1.14)$ & $0.85(0.64-1.13)$ & $0.87(0.66-1.15)$ \\
\hline
\end{tabular}

ESA, erythropoiesis-stimulating agent; Hgb, hemoglobin.

${ }^{a}$ Mircera doses were converted to darbepoetin doses using a 1.2:1 ratio, and darbepoetin doses were converted to epoetin doses using a 250:1 ratio.

${ }^{\mathrm{b}}$ Model 1: adjusted for DOPPS phase and accounting for facility clustering.

${ }^{\mathrm{c}}$ Model 2: adjusted for model $1+$ age, gender, vintage, 11 summary comorbidities and post dialysis weight.

${ }^{\mathrm{d}}$ Model 3: adjusted for model 2+ Kt/V, treatment time, hospitalization in past 3 months.

${ }^{\mathrm{e}}$ Model 4: adjusted for model 3+ CRP, albumin, TSAT, ferritin.

b Association between statin prescription and subsequent ESA resistance index by increasing levels of adjustment

\begin{tabular}{|c|c|c|c|c|c|c|c|}
\hline \multirow[t]{2}{*}{ Outcome } & \multirow[t]{2}{*}{ Statin $\mathrm{Rx}$} & \multirow[t]{2}{*}{ Number of patients } & \multirow[t]{2}{*}{ Average ERI } & \multicolumn{4}{|c|}{ Ratio of means (95\% CI) } \\
\hline & & & & model $1^{\mathrm{b}}$ & $\operatorname{model} 2^{c}$ & model $3^{\mathrm{d}}$ & $\operatorname{model} 4^{\mathrm{e}}$ \\
\hline \multirow[t]{2}{*}{$\log E R I^{a, f}$} & + & 585 & 10.1 & $0.92(0.87-0.97)$ & $0.95(0.90-1.00)$ & $0.94(0.89-0.99)$ & $0.94(0.89-0.99)$ \\
\hline & - & 3,017 & 10.7 & & & & \\
\hline
\end{tabular}

ESA, erythropoiesis-stimulating agent; ERI, ESA resistance index.

${ }^{\text {a }}$ Mircera doses were converted to darbepoetin doses using a 1.2:1 ratio, and darbepoetin doses were converted to epoetin doses using a 250:1 ratio.

${ }^{\mathrm{b}}$ Model 1: adjusted for DOPPS phase and accounting for facility clustering.

${ }^{\mathrm{c}}$ Model 2: adjusted for model $1+$ age, gender, vintage, 11 summary comorbidities and post dialysis weight.

${ }^{\mathrm{d}}$ Model 3: adjusted for model $2+\mathrm{Kt} / \mathrm{V}$, treatment time, hospitalization in past 3 months.

${ }^{\mathrm{e}}$ Model 4: adjusted for model 3+ CRP, albumin, TSAT, ferritin.

${ }^{\mathrm{f}} \mathrm{ERI}=\mathrm{ESA} /($ dry weight $\times \mathrm{Hgb})$.

definitions to describe their findings [27, 28]. The 2008 Japanese Society for Dialysis Therapy guidelines for renal anemia in CKD [29] defined hyporesponsiveness to ESA therapy as a failure to achieve anemia correction and the target Hgb level in HD patients despite the use of 9,000 $\mathrm{IU} /$ week of epoetin or $60 \mu \mathrm{g} /$ week of darbepoetin alfa. In 2012, the Kidney Disease: Improving Global Outcomes clinical practice guideline for anemia in CKD was released [30], defining ESA hyporesponsiveness as no increase in $\mathrm{Hgb}$ concentration from baseline after the first month of ESA treatment at an appropriate weight-based dosing. This definition was developed based on the secondary analysis results of the Trial to Reduce Cardiovascular Events with Aranesp Therapy [31] in which ESA hyporesponsiveness was associated with subsequent poor prognosis in CKD patients with type 2 diabetes mellitus [32].

This study suggested a small possible benefit of statins for improving ESA responsiveness. A retrospective multicenter cohort study in Europe suggested that ESA hyporesponsiveness secondary to hypoalbuminemia and an elevated serum CRP level might be a prognostic factor in HD patients [18]. Japanese national cohort data showed that mortality in HD patients is influenced by ESA hyporesponsiveness, independent of the interactive effects of ESA dose and Hgb level [16]. A subsequent meta-analysis of 10 studies in HD patients revealed that a higher ESA dose was associated with an approximately twofold increased mortality risk, independent of Hgb level [33]. Taken together, these findings suggest that statins may be useful as an adjuvant treatment for renal anemia in HD patients and could consequently improve their outcomes.

The current investigation has several strengths. First, the JDOPPS data were collected from a nationally representative sample of HD facilities in Japan, which provides broad generalizability of our findings for the Japanese population. Second, the detailed inclusion-exclusion criteria, which eliminated major factors influencing ESA hyporesponsiveness and targeted relatively stable and homogenous prevalent patients undergoing $\mathrm{HD}$, enhance the validity of the analytical results. 
However, several limitations to the present study warrant mention and should be considered when interpreting the findings. Oral medication data (e.g., statin $\mathrm{Rx}$ ) are collected once every 4 months in JDOPPS. This data collection is limited to prescription only and therefore does not capture adherence (including skipped/reduced dosing). If statin use is low relative to the prescription rate (due to poor adherence), then our estimates could be biased. We assumed that statins were not prescribed primarily to reduce ESA hyporesponsiveness in this population (i.e., no treatment-by-indication bias). However, other residual or unmeasured factors may have simultaneously influenced both statin use and either ESA dose or Hgb. Therefore, because of the observational study design, causal inference is limited regarding the effect of statin use on ESA hyporesponsiveness. The generalizability of our findings to non-Japanese populations also merits further study, as the rate of statin prescription is relatively low in Japan compared to that in the United States [9] and the prevalence of ESA hyporesponsiveness is also lower than in other regions [34]. Finally, the clinical effectiveness of statins for ESA resistance was marginal, suggesting only a possible role for statins in ESA hyporesponsiveness.

In summary, we examined the association between statin prescription and ESA hyporesponsiveness within a nationally representative cohort of Japanese HD patients (JDOPPS data). Our results support the hypothesis that statins may reduce ESA hyporesponsiveness in HD patients, but the magnitude of the adjusted association was small and further investigations are needed in different populations.

\section{Acknowledgments}

The DOPPS Program is supported by Amgen, Kyowa Hakko Kirin, and Baxter Healthcare. Additional support for specific projects and countries is provided by Amgen, Association of German
Nephrology Centres (Verband Deutsche Nierenzentren e.V.), AstraZeneca, European Renal Association-European Dialysis \& Transplant Association (ERA-EDTA), German Society of Nephrology (DGfN), Hexal AG, Janssen, Japanese Society for Peritoneal Dialysis (JSPD), Keryx, Proteon, Relypsa, Roche, Società Italiana di Nefrologia (SIN), Spanish Society of Nephrology, and Vifor Fresenius Medical Care Renal Pharma. Public funding and support is provided for specific DOPPS projects, ancillary studies, or affiliated research projects by Australia: National Health \& Medical Research Council (NHMRC), Canada: Canadian Institutes of Health Research (CIHR) and Ontario Renal Network, France: Agence Nationale de la Recherche, Thailand: Thailand Research Foundation (TRF), Chulalongkorn University Matching Fund, King Chulalongkorn Memorial Hospital Matching Fund, and the National Research Council of Thailand (NRCT), United Kingdom: National Institute for Health Research (NIHR) via the Comprehensive Clinical Research Network (CCRN), United States: National Institutes of Health (NIH) and Patient-Centered Outcomes Research Institute (PCORI). All support is provided without restrictions on publications.

We wish to express our appreciation to the steering committee members of JDOPPS, Drs. Kiyoshi Kurokawa, Akira Saito, Tadao Akizawa, Takashi Akiba, Shunichi Fukuhara, Masaaki Inaba, Kousaku Nitta, Masafumi Fukagawa, and Masaomi Nangaku. We are also grateful to the study nurses, physicians, and medical directors for the time and energy they have contributed to JDOPPS. JDOPPS was supported by research grants from Kyowa Hakko Kirin without restrictions on publications.

\section{Disclosure Statement}

T.H.: has consultancy agreements with Kyowa Hakko Kirin and has received honoraria from Kyowa Hakko Kirin, Baxter, Pfizer, Takeda and Novartis. J.Z., D.S.F., B.B., J.Z., and H.M.: nothing to declare. N.H.: has consultancy agreements with Kyowa Hakko Kirin and has received honoraria from Kyowa Hakko Kirin, Bayer, Daiichi Sankyo, Chugai, and Kowa. N.H. also received research funding from Kyowa Hakko Kirin, Chugai, Daiichi Sankyo, and Takeda. M.N.: has consultancy agreements with Kyowa Hakko Kirin, Astellas, Taisho, JT, Tanabe Mitsubishi, Daiichi Sankyo, and GSK, has received honoraria from Kyowa Hakko Kirin, Alexion, AstraZeneca, MSD, Daiichi Sankyo, Tanabe Mitsubishi, Chugai and JT, and has received research funding from Kyowa Hakko Kirin, Alexion, Kissei, Bayer, Daiichi Sankyo, Mochida, Chugai, JT and Takeda.

\section{References}

1 Baigent C, Keech A, Kearney PM, Blackwell L, Buck G, Pollicino C, Kirby A, Sourjina T, Peto R, Collins R, Simes R: Efficacy and safety of cholesterol-lowering treatment: prospective meta-analysis of data from 90,056 participants in 14 randomised trials of statins. Lancet 2005;366:1267-1278.

-2 Palmer SC, Craig JC, Navaneethan SD, Tonelli M, Pellegrini F, Strippoli GF: Benefits and harms of statin therapy for persons with chronic kidney disease: a systematic review and meta-analysis. Ann Intern Med 2012;157: 263-275.

3 Wanner C, Krane V, Marz W, Olschewski M, Mann JF, Ruf G, Ritz E: Atorvastatin in patients with type 2 diabetes mellitus undergoing hemodialysis. N Engl J Med 2005;353: 238-248.

- 4 Fellstrom BC, Jardine AG, Schmieder RE Holdaas H, Bannister K, Beutler J, Chae DW, Chevaile A, Cobbe SM, Gronhagen-Riska C, De Lima JJ, Lins R, Mayer G, McMahon AW, Parv- ing HH, Remuzzi G, Samuelsson O, Sonkodi S, Sci D, Suleymanlar G, Tsakiris D, Tesar V, Todorov V, Wiecek A, Wuthrich RP, Gottlow M, Johnsson E, Zannad F: Rosuvastatin and cardiovascular events in patients undergoing hemodialysis. N Engl J Med 2009;360:1395-1407.

5 Palmer SC, Navaneethan SD, Craig JC, Johnson DW, Perkovic V, Nigwekar SU, Hegbrant J, Strippoli GF: HMG CoA reductase inhibitors (statins) for dialysis patients. Cochrane Database Syst Rev 2013;9:CD004289. 
6 Wanner C, Tonelli M: KDIGO clinical practice guideline for lipid management in CKD: summary of recommendation statements and clinical approach to the patient. Kidney Int 2014;85:1303-1309.

7 Mason NA, Bailie GR, Satayathum S, BraggGresham JL, Akiba T, Akizawa T, Combe C, Rayner HC, Saito A, Gillespie BW, Young EW: HMG-coenzyme a reductase inhibitor use is associated with mortality reduction in hemodialysis patients. Am J Kidney Dis 2005; 45:119-126.

8 Hirakata H, Nitta K, Inaba M, Shoji T, Fujii H, Kobayashi S, Tabei K, Joki N, Hase H, Nishimura M, Ozaki S, Ikari Y, Kumada Y, Tsuruya K, Fujimoto S, Inoue T, Yokoi H, Hirata S, Shimamoto K, Kugiyama K, Akiba T, Iseki K, Tsubakihara Y, Tomo T, Akizawa T: Japanese Society for Dialysis Therapy guidelines for management of cardiovascular diseases in patients on chronic hemodialysis. Ther Apher Dial 2012;16:387-435.

9 US DOPPS Practice Monitor Statin Prescription in the US Hemodialysis Population Since, 2010, 2016.

10 Chang JW, Yang WS, Min WK, Lee SK, Park JS, Kim SB: Effects of simvastatin on highsensitivity C-reactive protein and serum albumin in hemodialysis patients. Am J Kidney Dis 2002;39:1213-1217.

11 Epstein M, Campese VM: Pleiotropic effects of 3-hydroxy-3-methylglutaryl coenzyme a reductase inhibitors on renal function. Am J Kidney Dis 2005;45:2-14.

12 Cattaneo D, Remuzzi G: Lipid oxidative stress and the anti-inflammatory properties of statins and ACE inhibitors. J Ren Nutr 2005; 15:71-76.

13 Sirken G, Kung SC, Raja R: Decreased erythropoietin requirements in maintenance hemodialysis patients with statin therapy. ASAIO J 2003;49:422-425.

14 Chiang CK, Yang SY, Peng YS, Hsu SP, Pai MF, Huang JW, Hung KY, Wu KD: Atorvastatin increases erythropoietin-stimulating agent hyporesponsiveness in maintenance hemodialysis patients: role of anti-inflammation effects. Am J Nephrol 2009;29:392-397.

-15 Tsouchnikas I, Dounousi E, Papakonstantinou S, Ioannou K, Kelesidis A, Kotzadamis N, Xanthopoulou K, Tsakiris D: Beneficial effect of atorvastatin on erythropoietin responsiveness in maintenance haemodialysis patients. Nephrology (Carlton) 2009;14:560-564.

16 Fukuma S, Yamaguchi T, Hashimoto S, Nakai S, Iseki K, Tsubakihara Y, Fukuhara S: Eryth- ropoiesis-stimulating agent responsiveness and mortality in hemodialysis patients: results from a cohort study from the dialysis registry in Japan. Am J Kidney Dis 2012;59: 108-116.

17 Reuter SE, Faull RJ, Ranieri E, Evans AM: Endogenous plasma carnitine pool composition and response to erythropoietin treatment in chronic haemodialysis patients. Nephrol Dial Transplant 2009;24:990-996.

18 Panichi V, Rosati A, Bigazzi R, Paoletti S, Mantuano E, Beati S, Marchetti V, Bernabini G, Grazi G, Rizza GM, Migliori M, Giusti R, Lippi A, Casani A, Barsotti G, Tetta C: Anaemia and resistance to erythropoiesis-stimulating agents as prognostic factors in haemodialysis patients: results from the RISCAVID study. Nephrol Dial Transplant 2011;26:2641-2648.

19 Choi P, Farouk M, Manamley N, Addison J: Dose conversion ratio in hemodialysis patients switched from darbepoetin alfa to PEG-epoetin beta: AFFIRM study. Adv Ther 2013;30:1007-1017.

20 Bock HA, Hirt-Minkowski P, Brunisholz M, Keusch G, Rey S, von Albertini B: Darbepoetin alpha in lower-than-equimolar doses maintains haemoglobin levels in stable haemodialysis patients converting from epoetin alpha/beta. Nephrol Dial Transplant 2008;23: 301-308.

21 Valeri L, Vanderweele TJ: Mediation analysis allowing for exposure-mediator interactions and causal interpretation: theoretical assumptions and implementation with SAS and SPSS macros. Psychol Methods 2013;18:137150.

22 Raghunathan TE, Solenberger PW, Van Hoewyk J: IVEware: Imputation and Variance Estimation Software Users Guide. Michigan, Survey Research Center, Institute for Social Research, 2002.

23 Rubin DB: Multiple Imputation for Nonresponse in Surveys. New York, J. Wiley \& Sons, 1987.

24 SAS Institute. SAS/STAT User's Guide, Version 8, Vol. 2. Cary, SAS Institute, 2000.

25 Kimachi M, Fukuma S, Yamazaki S, Yamamoto Y, Akizawa T, Akiba T, Saito A, Fukuhara S: Minor elevation in C-reactive protein levels predicts incidence of erythropoiesisstimulating agent hyporesponsiveness among hemodialysis patients. Nephron 2015;131: 123-130.

-26 Bradbury BD, Critchlow CW, Weir MR, Stewart R, Krishnan M, Hakim RH: Impact of elevated C-reactive protein levels on erythro- poiesis- stimulating agent (ESA) dose and responsiveness in hemodialysis patients. Nephrol Dial Transplant 2009;24:919-925.

27 Locatelli F, Aljama P, Barany P, Canaud B, Carrera F, Eckardt KU, Horl WH, Macdougal IC, Macleod A, Wiecek A, Cameron S: Revised European best practice guidelines for the management of anaemia in patients with chronic renal failure. Nephrol Dial Transplant 2004;19(suppl 2):ii1-ii47.

28 KDOQI; National Kidney Foundation: II. Clinical practice guidelines and clinical practice recommendations for anemia in chronic kidney disease in adults. Am J Kidney Dis 2006;47(5 suppl 3):S16-S85.

29 Tsubakihara Y, Nishi S, Akiba T, Hirakata H, Iseki K, Kubota M, Kuriyama S, Komatsu Y, Suzuki M, Nakai S, Hattori M, Babazono T, Hiramatsu M, Yamamoto $H$, Bessho M, Akizawa T: 2008 Japanese Society for Dialysis Therapy: guidelines for renal anemia in chronic kidney disease. Ther Apher Dial 2010;14:240-275.

30 KDOQI US commentary on the 2012 KDIGO clinical practice guideline for anemia in CKD. Kidney Int Suppl 2012;2:279.

31 Pfeffer MA, Burdmann EA, Chen CY, Cooper ME, de Zeeuw D, Eckardt KU, Feyzi JM, Ivanovich P, Kewalramani R, Levey AS, Lewis EF, McGill JB, McMurray JJ, Parfrey P, Parving $\mathrm{HH}$, Remuzzi G, Singh AK, Solomon SD, Toto R: A trial of darbepoetin alfa in type 2 diabetes and chronic kidney disease. $\mathrm{N}$ Engl J Med 2009;361:2019-2032.

32 Solomon SD, Uno H, Lewis EF, Eckardt KU, Lin J, Burdmann EA, de Zeeuw D, Ivanovich P, Levey AS, Parfrey P, Remuzzi G, Singh AK, Toto R, Huang F, Rossert J, McMurray JJ, Pfeffer MA: Erythropoietic response and outcomes in kidney disease and type 2 diabetes. N Engl J Med 2010;363: 1146-1155.

33 Koulouridis I, Alfayez M, Trikalinos TA, Balk EM, Jaber BL: Dose of erythropoiesis-stimulating agents and adverse outcomes in CKD: a metaregression analysis. Am J Kidney Dis 2013;61:44-56.

34 Fuller DS, Bieber BA, Pisoni RL, Li Y, Morgenstern $\mathrm{H}$, Akizawa T, Jacobson SH, Locatelli F, Port FK, Robinson BM: International comparisons to assess effects of payment and regulatory changes in the United States on anemia practice in patients on hemodialysis: the dialysis outcomes and practice patterns study. J Am Soc Nephrol 2016;27:22052215. 